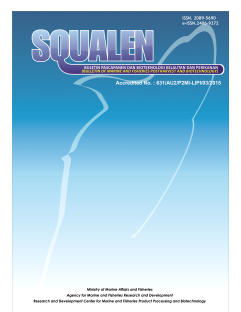

www.bbp4b.litbang.kkp.go.id/squalen-bulletin

\title{
POTENCY OF ACTINOMYCETES FROM DEEPSEA SEDIMENT OF MAKASSAR STRAIT FOR PRODUCING ANTIMICROBIAL SUBSTANCES
}

\author{
Ariani Hatmanti ${ }^{1}$, Puspita Lisdiyanti $^{2}$, Jaka Widada ${ }^{3}$, and Subagus Wahyuono ${ }^{4}$ \\ ${ }^{1}$ Research Center for Oceanography, Indonesian Institute of Sciences, \\ Jl. Pasir Putih I Ancol Timur, Jakarta, Indonesia \\ ${ }^{2}$ Research Center for Biotechnolog, Indonesian Instritute of Sciences, \\ Jl. Raya Bogor Km. 46, Cibinong Science Center, Cibinong 16911, West Java, Indonesia \\ ${ }^{3}$ Faculty of Agriculture Gadjahmada University, Bulaksumur, Yogyakarta, Indonesia \\ ${ }^{4}$ Faculty of Pharmacy Gadjahmada University, Bulaksumur, Yogyakarta, Indonesia \\ Article history: \\ Received: 8 May 2018; Revised: 23 July 2018; Accepted: 28 August 2018
}

\begin{abstract}
A study on isolation of actinomycetes from sediments of Makassar Strait have been conducted with regard to research project called Widya Nusantara Exploration (EWIN) in May-June 2013 and November 2014. The objectives of this research were to screen antimicrobial activity of 36 actinomycetes from sediments of Makassar Strait, characterized the potential isolates, and determined the metabolites produced by the selected isolate. The antimicrobial screening was conducted using agar diffusion method, while characterization of the best five of actinomycetes were using APIZYM Kit, Scanning Electron Microscope, and FTIR. Five isolates retrieved from this research had ability to inhibit the growth of four microbial testing: Escherichia coli, Bacillus subtilis, Staphyllococcus aureus and Candida albicans. The highest capability was shown by the MACMK-43 isolate that had 16S rRNA gene sequence similarity of $97.85 \%$ to Streptomyces violacens. The result shows that, the active fraction contained of 4 amino-5-cyano-6-(4'methoxyphenyl)-1-methyl-2.3-dihydropyrrolo [2,3-B] pyridine, which is commercially used for bactericide and antihistamine.
\end{abstract}

Keywords: antimicrobes, actinomycetes, Streptomyces violascens, deepsea sediment

\section{Introduction}

Actinomycetes are the group of high $\mathrm{G}+\mathrm{C}$ content gram positive bacteria, in which have an ability to produce diverse bioactive compounds, such as antibiotics, antifungals, antiparasitic, and anticancer drugs (Cragg, Kingston, \& Newman, 2011; Helaly, Pesic, Fiedler, \& Sussmuth, 2011; Gao et al., 2012; Lu et al., 2012). Up to now, $45 \%$ of the bioactive compounds produced by microbes were produced by actinomycetes, so actinomycetes are still major natural antimicrobial producer (Berdy, 2005). Manivasagan, Jayachandran, Kannan \& Se-Kwon, (2013) reported that among 23.000 antimicrobial produced by microbes, more than 10.000 isolated from actinomycetes, especially Genera Streptomyces.
The decline in the discovery of new substances obtained from terrestrial actinomycetes has led scientists and researchers to focus on exploring actinomycetes from extreme environments. Marine is one of the environments that being studied as a source of actinomycetes isolation. The marine environment attracts the attention of researchers as a source of microbial isolation, and it has been reported that marine microbes including actinomycetes are useful for screening new secondary metabolites (Lam, 2006; Blunt et al., 2007; Khan et al., 2011).

Several studies have shown that actinomycetes isolated from the marine environment are metabolically active and have adapted to marine life (Bull, Stach, Ward, \& Goodfellow, 2005; Lam, 2006; Valli et al., 2012). Marine actinomycetes are widely distributed

\footnotetext{
${ }^{\star}$ Corresponding author.

E-mail:ariehatmanti@gmail.com
} 
in a variety of marine habitats from marine sand (Hong, Lee, Yim, Chun, \& Lee, 2008), mangrove sediments (Hong et al., 2009; Hong, 2013; Azman, Othman, Velu, Cha, \& Lee, 2015; Hamada et al., 2015a; Hamada et al., 2015b), seawater (Zhang, Xi, Ruan, \& Huang, 2012), coastal sediments (Yu et al., 2015), and deep sea sediments (Pathom-aree et al., 2006; Bredholt et al., 2007 ; Luo et al., 2011; Zhang, Zhang, Yin, \& Wang, 2015; Chen et al., 2016). The increasing number of studies on marine actinomycetes indicates that marine environment including the deep ocean, is a significant source for finding and discovering both the marine actinomycetes diversity and its secondary metabolites product. (Skropeta \& Wei, 2014; Xu, Ye, Han, Deng, \& Hong, 2014). In the last few years, several reports on the discovery of antimicrobial compounds of actinomycetes isolated from some deepsea sediments are shown in Table 1. These potential strains were isolated from marine sediments in deepsea of South China Sea and Indian Ocean. This phenomenon was confirmed by Kamjam Sivalingam, Deng, and Hong(2017), that the deep ocean is a hot spot for hunting the source of marine origin actinomycetes and its new secondary metabolites, due to its uniqueness and extreme environment.

A study on exploring antimicrobial producing actinomycetes obtained from the sediments with depth level between 150-3.366 meters of Makassar Strait have been done. This research aimed to screen antimicrobial activity of 36 actinomycetes from sediments of Makassar Strait, characterized the potential isolates, and characterized their metabolites product. The results of this study hopefully will enrich the information about potential actinomycetes from the deepsea waters of Indonesian territory.

\section{Material and Methods}

\subsection{Microbial Strains}

Thirty-six marine actinomycetes strains used in this study were come from collections of Marine Microbiology Laboratory of the Oceanography Research Center LIPI, Ancol and Indonesian Culture Collections (InaCC) Biology Research Center LIPI. The medium used for isolation were Actinomycetes Isolation Agar (AIA, Hymedia, India) and NBRC 802 media (Hamada, Shibata, Tamura, \& Suzuki, 2013). All isolation media were added with nalidixic acid and cycloheximide to hamper bacterial growth (Hayakawa, Momose, Yamazaki, \& Nonomura, 1996). Molecular identification of the isolates were conducted using analysis of $16 \mathrm{~S}$ rRNA gene sequencing. The bacterial testing used were Escherichia coli, Bacillus subtilis,

Table 1. Actinomycetes isolated from deepsea sediments and its antimicrobial compounds

\begin{tabular}{|c|c|c|c|}
\hline Antimicrobes & Name of Isolate & $\begin{array}{c}\text { Source } \\
\text { (deepsea level in } \mathrm{m} \text { ) }\end{array}$ & Reference \\
\hline Pseudono-cardians A-C & Pseudonocardia sp & $\begin{array}{l}\text { South China Sea } \\
(3,258 \mathrm{~m})\end{array}$ & Li et al., 2011 \\
\hline Indole alkaloid & Serinicoccus profundi sp. nov. & $\begin{array}{l}\text { Indian Ocean } \\
(5,368 \mathrm{~m})\end{array}$ & Yang et al., 2013 \\
\hline Lobophorins H dan I & Streptomyces sp. $12 \mathrm{~A} 35$ & $\begin{array}{l}\text { South China Sea } \\
(2,134 \mathrm{~m})\end{array}$ & Pan et al., 2013 \\
\hline Champacyclin & Streptomyces strain C42 & $\begin{array}{l}\text { Baltic Sea } \\
(241 \mathrm{~m})\end{array}$ & Pesic et al., 2013 \\
\hline Abyssomycins J-L & Verrucosispora sp. & $\begin{array}{l}\text { South China Sea } \\
(2,733 \mathrm{~m})\end{array}$ & Wang et al., 2013 \\
\hline D. sotamides B-D & Streptomyces scopuliridis & $\begin{array}{l}\text { South China Sea } \\
(3,536 \mathrm{~m})\end{array}$ & Song et al., 2014 \\
\hline Bafilomycins B1 \& C1 & Streptomyces cavourensis NA4 & $\begin{array}{l}\text { South China Sea } \\
(1.464 \mathrm{~m})\end{array}$ & Pan et al., 2015 \\
\hline Dehydroxy-aquayamycins & Streptomyces sp. SCSIO 11594 & $\begin{array}{l}\text { South China Sea } \\
(2.403 \mathrm{~m})\end{array}$ & Song et al., 2015 \\
\hline
\end{tabular}


and Staphylococcus aureus, while fungal testing used was Candida albicans.

\subsection{Fermentation and Extraction of Active Substance}

Fermentation was carried out using medium of Starch Yeast Pepton Broth (SYP Broth), which contained of a $10 \mathrm{gr}$ soluble starch, 4 gr yeast extract, $2 \mathrm{gr}$ pepton, and aquadest up to $1000 \mathrm{~mL}$ of solution. Medium was sterilized in an autoclave at $121^{\circ} \mathrm{C}, 2$ atm pressure, for 15 minutes, then settled at room temperature and ready to be used. One pure isolate was inoculated into the pre-culture medium containing $5 \mathrm{ml}$ of SYP Broth medium, then incubated at $30^{\circ} \mathrm{C}$ for 2 days ( 48 hours) in the incubator shaker at 100 $\mathrm{rpm}$. Thereafter, the entire pre-cultured medium was transferred into a fermentation medium containing 100 $\mathrm{mL}$ of SYP Broth and incubated at $30^{\circ} \mathrm{C}$ in a shaker incubator at $100 \mathrm{rpm}$ for 10 days (240 hours). The cultures were then extracted by adding approximately $1: 1=$ media:ethyl acetate. The flasks were shaken at $30{ }^{\circ} \mathrm{C}$ and $100 \mathrm{rpm}$ for 12 hours, then ethyl acetate fractions were transferred into new flasks. Extracts were evaporated using vacuum evaporator at temperature of $30^{\circ} \mathrm{C}$ up to $10 \mathrm{ml}$. Raw material was then transferred into a vial, evaporated at room temperature to dry. $1 \mathrm{ml}$ of methanol was added into each vial, and then dissolved and homogenized using vortex. The residual metabolite which was not soluble in methanol, was dissolved by $1 \mathrm{ml}$ of DCM (Dichloromethane), and then homogenized using vortex. The extracts were stored at $4^{\circ} \mathrm{C}$ and ready to be screened.

\subsection{Antimicrobial Screening}

Antimicrobial screening was measured by agar diffusion method (Kanoh, Adachi, Katsuta, \& Shizuri, 2008). The E. coli, S. aureus, and B. subtilis microbial testing used for screening were grown on Nutrient Agar (NA) and Nutrient Broth (NB) medium, while $C$. albicans was grown on Potato Dextrose agar (PDA) medium or Potato Dextrose Broth (PDB) medium. Microbial testing were incubated at $37^{\circ} \mathrm{C}$ for $1 \times 24$ hours for E. coli, S. aureus, and B. subtilis, whereas for $C$. albicans for $2 \times 24$ hours. Petri dishes containing NA medium were smeared with each microbial testing of E. coli, S. aureus, and B. subtilis, while PDA medium was spread with $C$. albicans. Those pathogenic microbials were spreaded aseptically on surface of medium by using sterile cotton bud. A total of $15 \mathrm{~mL}$ of extract was dripped onto a $6 \mathrm{~mm}$ thick diameter paper disc, then dried in an aseptic laminar airflow. Each of the paper discs was then placed on agar medium that has been smeared with microbial testing. Petri dishes containing each pathogenic microbial were used as positive control. Paper discs containing of methanol and DCM solvent that put in the petri dishes containing with pathogenic microbial were used as negative control. The petri dishes were incubated at $37^{\circ} \mathrm{C}$ for $2 \times 24$ hours, and observed for every 24 hours. Each emerging clear zone was measured and recorded as an inhibition zone.

\subsection{Semi Quantitative Enzymatic Characterization}

The enzymatic reaction test was performed using APIZYM strip (Biomereux). The system consists of a strip with 20 microwells, which its base contains of the enzymatic substrate and its buffer. The enzymatic tests are inoculated with a dense suspension of organisms, which is used to rehydrate the enzymatic substrates. The metabolic and products produced during the incubation period are detected through coloured reactions revealed by the addition of reagents.

About $5 \mathrm{ml}$ of distilled aquadest was poured in an incubation box (a closed mica box) to create a moist atmosphere. The APIZYM kit strip was then placed in the incubation box. The inoculation of actinomycetes culture into the strip was performed using a sterile micropipette. A total of $65 \mu \mathrm{l}$ of liquid actinomycetes cultures were introduced into each well. After inoculation, the incubation box was closed and incubated for $4-4.5$ hours at $37^{\circ} \mathrm{C}$. After incubation, one drop of ZYM A reagent and one drop of ZYM B reagent were added to each well. The strips were stand about 5 minutes, then the colour formed and compared with the colour chart provided by manufacture (Humble, King, \& Phillips, 1977).

\subsection{Fractionation, Purification and Determination of Active Compounds}

The fractionation and partial purification of the active compound was carried out by silica gel chromatography column using solvent hexane : ethyl acetate $=1: 1$, while the characterization of the active fraction was performed by using Gas Chromatography Mass Spectrophotometer (GCMS) (7890B GC, Agilent Technologies USA) with autosampler and Chemstation Data System. The peaks produced by this measurement was compared to library database in the tool. 
Table 2. Results of antimicrobial assay of 36 strains of actinomycetes from deepsea sediment of Makassar Strait against E. coli, B. subtilis, S. aureus, and C. albicans

\begin{tabular}{|c|c|c|c|c|c|c|c|c|}
\hline \multirow{2}{*}{ No } & \multirow{2}{*}{ Strains code } & \multirow{2}{*}{ TopHt Taxon } & \multirow{2}{*}{ TopHt Strain } & \multirow{2}{*}{$\begin{array}{l}\text { Identity } \\
\text { (\%) }\end{array}$} & \multicolumn{4}{|c|}{ Diameter (mm) } \\
\hline & & & & & E coli & S aureus & B subtilis & C. albicans \\
\hline 1 & MACMK-08 & Mcromonospora chalcea & DSM43026 & 99.71 & - & - & - & 8 \\
\hline 2 & MACMK-09 & Gordonia didemni & $\mathrm{B} 204^{\top}$ & 98.52 & - & - & - & 7.5 \\
\hline 3 & MACMK-14* & Micrococcus yumanensis & ${\text { YM } 65004^{\top}}^{\top}$ & 99.78 & 26.33 & 1.2 & 0.78 & 26.6 \\
\hline 4 & MACMK-19 & Mcromonospora tulbaghiae & $\mathrm{DSM} 45142^{\top}$ & 99.18 & - & - & - & 8 \\
\hline 5 & MACMK-२० & Nocardiopsis alba & $\mathrm{DSM} 4337^{\top}$ & 99.93 & - & - & - & - \\
\hline 6 & MACMK-25 & Mcromonospora tulbaghiae & $\mathrm{DSM} 45142^{\top}$ & 98.52 & 9.7 & - & - & 11.1 \\
\hline 7 & MACMK-32 & Mcromonospora auratinigra & $\mathrm{DSM} 44815^{\top}$ & 98.83 & - & - & - & 11 \\
\hline 8 & MACMK-37* & Micromonospora chalcea & $\mathrm{DSM}^{4} 43026^{\top}$ & 99.64 & 19.9 & 1 & 0.7 & 223 \\
\hline 9 & MACMK-43* & Streptomyces vidascens & ISP $5183^{\top}$ & 97.58 & 21.13 & 1.2 & 0.7 & 28.95 \\
\hline 10 & MACMK-52 & Mcromonospora tulbaghiae & DSM45142 ${ }^{\top}$ & 99.27 & 1.19 & - & - & \\
\hline 11 & MACMK-53 & Mcromonospora tulbaghiae & DSM45142 ${ }^{\top}$ & 99.35 & 0.88 & - & - & 10.7 \\
\hline 12 & MACMK-54 & Mcromonosporatulbaghiae & $\mathrm{DSM} 45142^{\top}$ & 94.73 & 1.7 & - & - & 7.3 \\
\hline 13 & MACMK-55P & Mcromonosporatulbaghiae & DSM45142 ${ }^{\top}$ & 99.42 & 8.2 & - & - & - \\
\hline 14 & MACMK-55C & Mcromonospora chalcea & DSM43026 ${ }^{\top}$ & 99.64 & - & - & - & - \\
\hline 15 & MACMK-56 & Streptomyces diastaticus subsp. Diastaticus & NBRC $3714^{\top}$ & 98.92 & - & - & - & 10.2 \\
\hline 16 & MACMK-57 & Arthrobacter subterraneus & $\mathrm{CH}^{\top}$ & 99.77 & 10.8 & - & - & 8.9 \\
\hline 17 & MACMK-58 & Streptomyces diastaticus subsp. Ardesiacus & NRRL B-1773 ${ }^{\top}$ & 99.64 & - & - & - & 8.2 \\
\hline 18 & MACMK-60 & Verucosisporagifhomensis & $\mathrm{DSM} 44337^{\top}$ & 99.18 & 18.6 & - & - & - \\
\hline 19 & MACMK-61 & Mcromonospora wenchangensis & CCTCCAA2012002 $^{\top}$ & 100 & - & - & - & 1 \\
\hline 20 & MACMK-62 & Mcromonospora tulbaghiae & DSM45142 ${ }^{\top}$ & 99.48 & - & - & - & - \\
\hline 21 & MACMK-63 & Mcromonospora tulbaghiae & DSM45142 ${ }^{\top}$ & 100 & - & - & - & 8 \\
\hline 22 & MACMK-64 & Mcromonospora maritime & D10-9-5 ${ }^{\top}$ & 99.85 & - & - & - & 7.9 \\
\hline 23 & MACMK-65 & Verucosispora fiedleri & $\mathrm{MG}-37^{\top}$ & 99.56 & - & - & - & 10.3 \\
\hline 24 & MACMK-66 & Mcromonospora chalcea & $\mathrm{DSM}_{43026^{\top}}$ & 99.71 & - & - & - & - \\
\hline 25 & MACMK-67 & Mcromonospora chalcea & $\mathrm{DSM}_{43026^{\top}}$ & 99.71 & - & - & - & 7 \\
\hline 26 & MACMK-68 & Mcromonospora tulbaghiae & DSM $45142^{\top}$ & 99.35 & - & - & - & 8.6 \\
\hline 27 & MACMK-69 & Mcromonosporatulbaghiae & DSM45142 ${ }^{\top}$ & 99.11 & - & - & - & 9.6 \\
\hline 28 & MACMK-70 & Luteipulveratus halotolerans & $\mathrm{C} 296001^{\top}$ & 99.93 & 10.9 & - & - & 9.4 \\
\hline 29 & MACMK-71 & Verucosisporagifhomensis & $\mathrm{DSM} 44337^{\top}$ & 99.71 & 9.3 & - & - & 7.5 \\
\hline 30 & MACMK-72* & Verrucosispora gifhornensis & 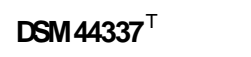 & 99.85 & 21.8 & 1.05 & 0.8 & 28.9 \\
\hline 31 & MACMK-73 & Mcromonosporatulbaghiae & DSM45142 ${ }^{\top}$ & 99.49 & - & - & - & 0.65 \\
\hline 32 & MACMK-74 & Verucosisporagifhomensis & $\mathrm{DSM} 44337^{\top}$ & 99.86 & - & - & - & 7.7 \\
\hline 33 & MACMK-75 & Luteipulveratus halotolerans & $\mathrm{C} 296001^{\top}$ & 100 & - & - & - & - \\
\hline 34 & MACMK-77 & Mcromonospora terminaliae & $\mathrm{TMST}^{\top}$ & 99.26 & - & - & - & 9.6 \\
\hline 35 & MACMK-80* & Kytococcus sedentarius & DSM20547 $^{\top}$ & 99.78 & 17.9 & 0.95 & 0.7 & 21.9 \\
\hline 36 & MACMK-81 & Mcromonospora maritime & D10-9-5 ${ }^{\top}$ & 100 & - & - & - & - \\
\hline
\end{tabular}

${ }^{*}$ Bold are the best five of actinomycetes strains; ${ }^{\top}$ are strain's type of top hits strain

\subsection{Scanning Electron Microscopy}

Morphological performance of strain Streptomyces violascens MACMK-43, obtained from deep floor sediments of Makassar Strait was observed by Scanning Electron Microscopy (JSM 5310 LV, JEOL Japan). 

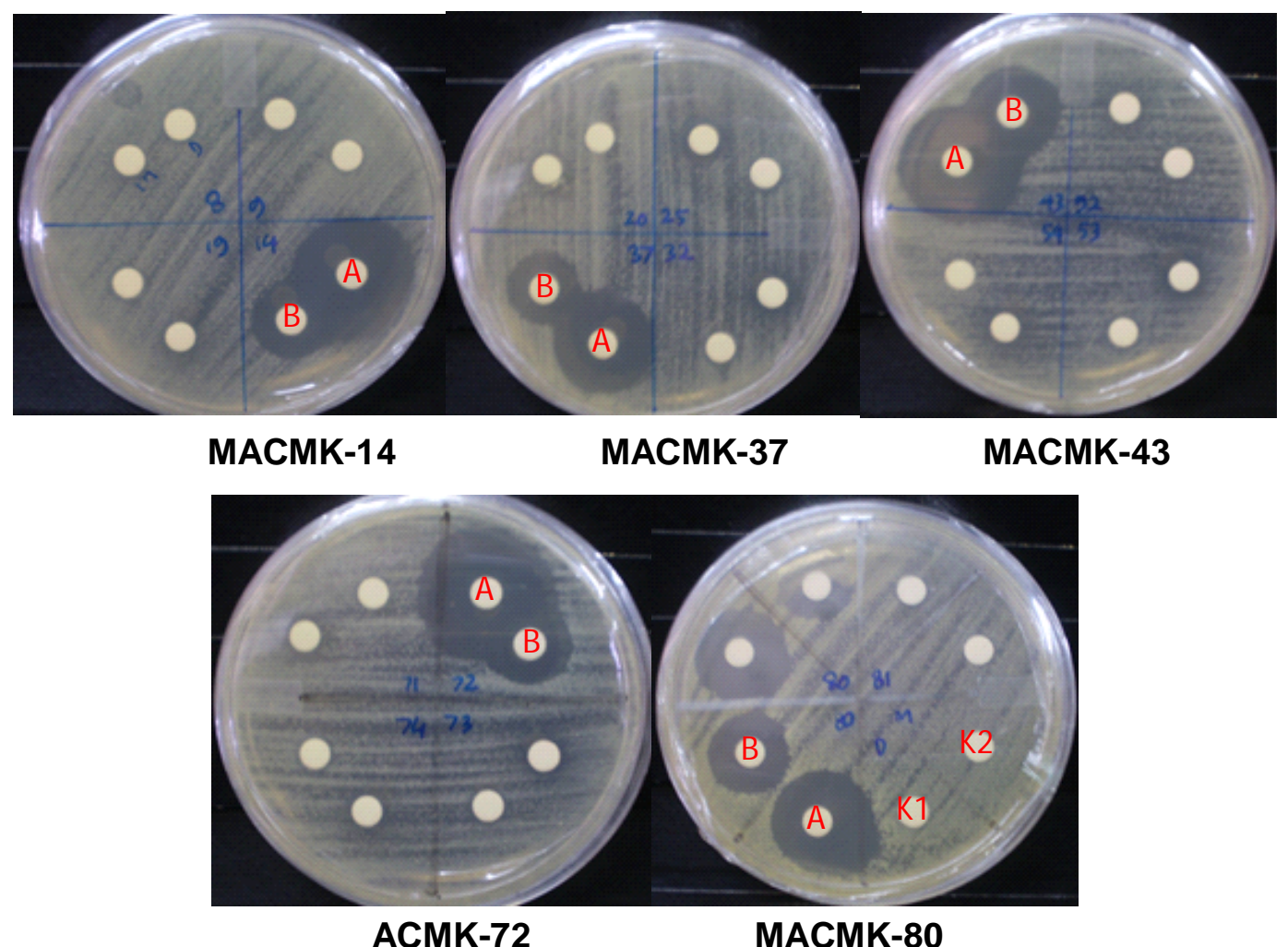

Figure 1. Clear zone showed by isolate MAMCK-14, MACMK-37, MACMK-43, MACMK-72 dan MACMK-80 against pathogenic microbial testing $C$. Albicans $A$ : raw extract in methanol solvent, $B$ : raw extract in DCM solvent, $\mathrm{K} 1$ : positive control 1 (solvent methanol), $\mathrm{K} 2$ : positive control 2 (DCM solvent).

\section{Results and Discussion}

\subsection{Capability of Actinomycetes on Producing Antimicrobial Compounds}

Thirty-six isolates of actinomycetes, which have been isolated from the Makassar Strait seafloor sediments with depths on between 150 and 3,366 meters, were divided into 9 genera including Micromonospora, Verrucosispora, Streptomyces, Luteipulveratus, Nocardiopsis, Micrococcus, Gordonia, Kytococcus, and Arthrobacter (Hatmanti, Lisdiyanti, Widada, \& Wahyuono, 2018). The 36 isolates have been tested for inhibition of 3 pathogenic bacterial testing and 1 pathogenic fungus testing, i.e., E. coli, $S$. aureus, $B$. subtilis and $C$. albicans. The results are shown in Table 2. From 36 strains, 14 strains inhibited the growth of $E$. coli, 5 strains inhibited $S$. aureus and $B$. subtilis, and 27 strains inhibited $C$. albicans. Based on Table 2, five best isolates were selected which were capable of inhibiting all four types of pathogens and had greatly inhibitory power by showing larger clear zones than others. The strains were MACMK-14 (Micrococcus yunnanensis $99.78 \%$ ),
MACMK-37 (Micromonospora chalcea, 99.64\%), MACMK-43 (Streptomyces violascens, 97.58\%), MACMK-72 (Verrucosispora gifhornensis, 99.85\%), and MACMK-80 (Kytococcus sedentarius, 99.78\%). Figure 1 shows clear zone produced by five leading strains inhibiting $C$. albicans, compared to others. The clear zone indicates that actinomycetes strains retrieved from marine sediments of Makassar Strait are able to inhibit the growth of $C$. albicans. Streptomyces violascens MACMK-43 strain was selected for further analysis on producing antimicrobial compound.

\subsection{Characterization of the Best Five Actinomycetes Producing Antimicrobial Compounds: The Enzymatic Activity}

The enzymatic activity of the five selected strains was tested using APIZYM Kit (Biomereux). The photographs of the test results are shown in Figure 2 and the test readings are listed in Table 3. Semi quantitative readings show that there are two unique isolates, i.e.: MACMK-43 strain which has stronger and more diverse enzymatic activity against some 


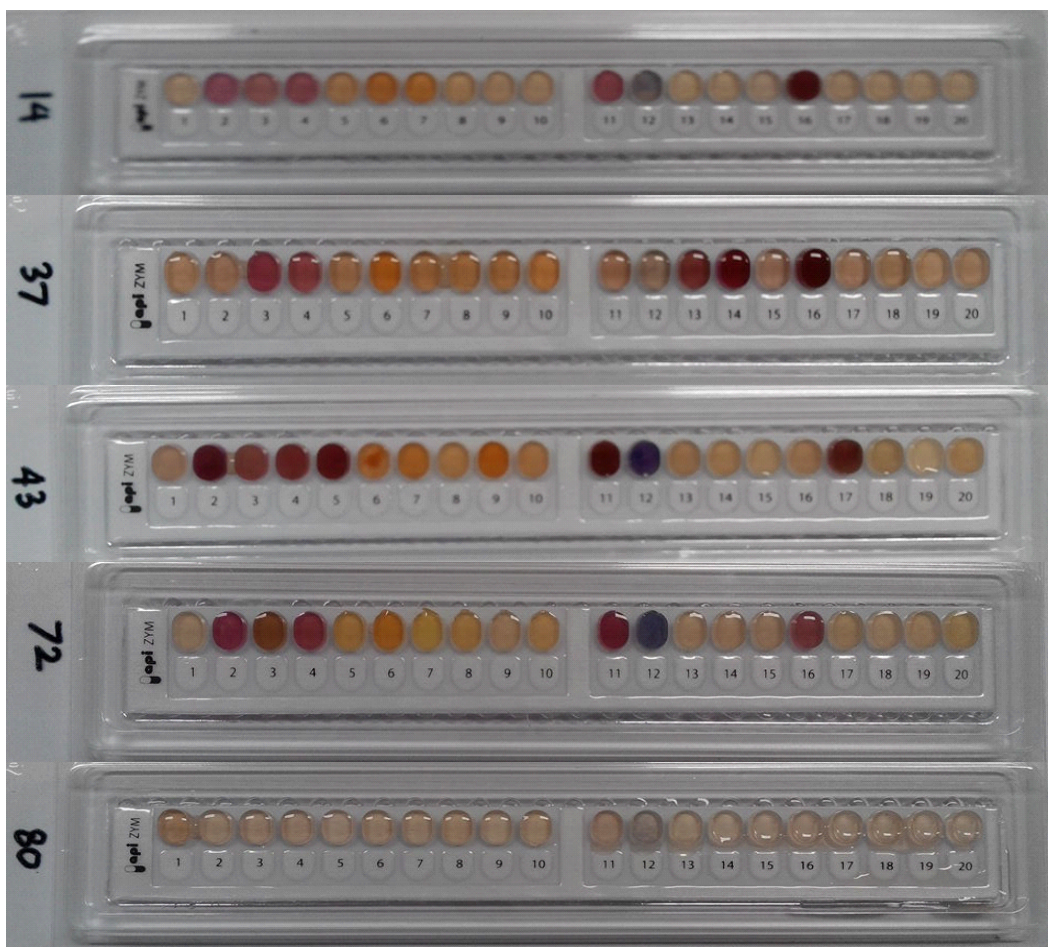

Figure 2. The enzymatic test of 5 preeminent isolates using APIZYM strip (Biomereux) i.e.: MACMK-14, MACMK-37, MACMK-43, MACMK-72 and MACMK-80.

Table 3. Results of enzymatic reaction of the best 5 isolates using APIZYM Kit, compared to colour chart provided by manufacture (Biomereux)

\begin{tabular}{|c|c|c|c|c|c|c|}
\hline \multirow{2}{*}{ No } & \multirow{2}{*}{ Enzyme } & \multicolumn{5}{|c|}{ Quantity of hydrolysed substrate } \\
\hline & & MACMK-14 & MACMK-37 & MACMK-43 & MACMK-72 & MACMK-80 \\
\hline 1 & Control & 0 & 0 & 0 & 0 & 0 \\
\hline 2 & Alkaline phosphatase & 3 & 1 & 5 & 5 & 1 \\
\hline 3 & Esterase (C4) & 3 & 5 & 3 & 5 & 1 \\
\hline 4 & Esterase Lipase (C8) & 3 & 3 & 5 & 5 & 1 \\
\hline 5 & Lipase (C14) & 1 & 1 & 5 & 1 & 0 \\
\hline 6 & Leucine arylamidase & 5 & 3 & 5 & 3 & 0 \\
\hline 7 & Valine arylamidase & 3 & 1 & 5 & 1 & 0 \\
\hline 8 & Cystine arylamidase & 0 & 1 & 1 & 1 & 0 \\
\hline 9 & Trypsin & 0 & 1 & 5 & 1 & 0 \\
\hline 10 & $\alpha$-chymotrypsin & 0 & 1 & 1 & 1 & 0 \\
\hline 11 & Acid phosphatase & 3 & 1 & 5 & 5 & 1 \\
\hline 12 & Naphthol-AS-BI-phosphohydrolase & 3 & 1 & 5 & 5 & 1 \\
\hline 13 & $\alpha$-galactosidase & 0 & 5 & 0 & 0 & 0 \\
\hline 14 & $\beta$-galactosidase & 0 & 5 & 0 & 0 & 0 \\
\hline 15 & $\beta$-glucuronidase & 0 & 0 & 0 & 0 & 0 \\
\hline 16 & $\alpha$-glucosidase & 5 & 5 & 0 & 5 & 1 \\
\hline 17 & $\beta$-glucosidase & 0 & 0 & 5 & 0 & 0 \\
\hline 18 & $\mathrm{~N}$-acetyl- $\beta$-glucosaminidase & 0 & 3 & 3 & 0 & 0 \\
\hline 19 & $\alpha$-mannosidase & 0 & 0 & 0 & 0 & 0 \\
\hline 20 & $\alpha$-fucosidase & 0 & 0 & 0 & 0 & 0 \\
\hline
\end{tabular}

Note: Value in the column indicate the quantity of hydrolysed substrates: $0=0$ nanomoles, $1=5$ nanomoles, $2=10$ nanomoles, $3=20$ nanomoles, $4=30$ nanomoles, $5=>40$ nanomoles 


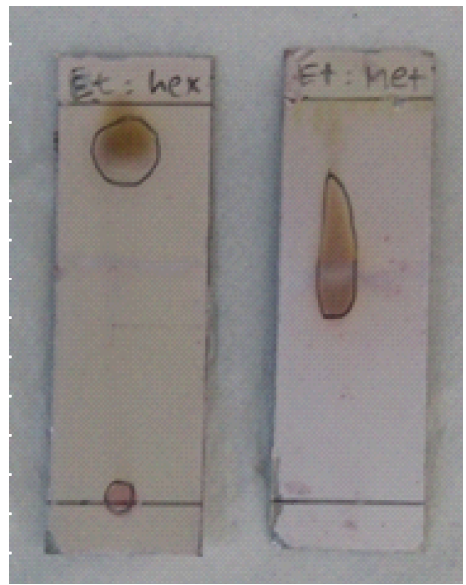

Figure 3. Performance of TLC for crude extract produced by MACMK-43 by several solvents. A (hexane: ethyl acetate); B (methanol : ethyl acetate).

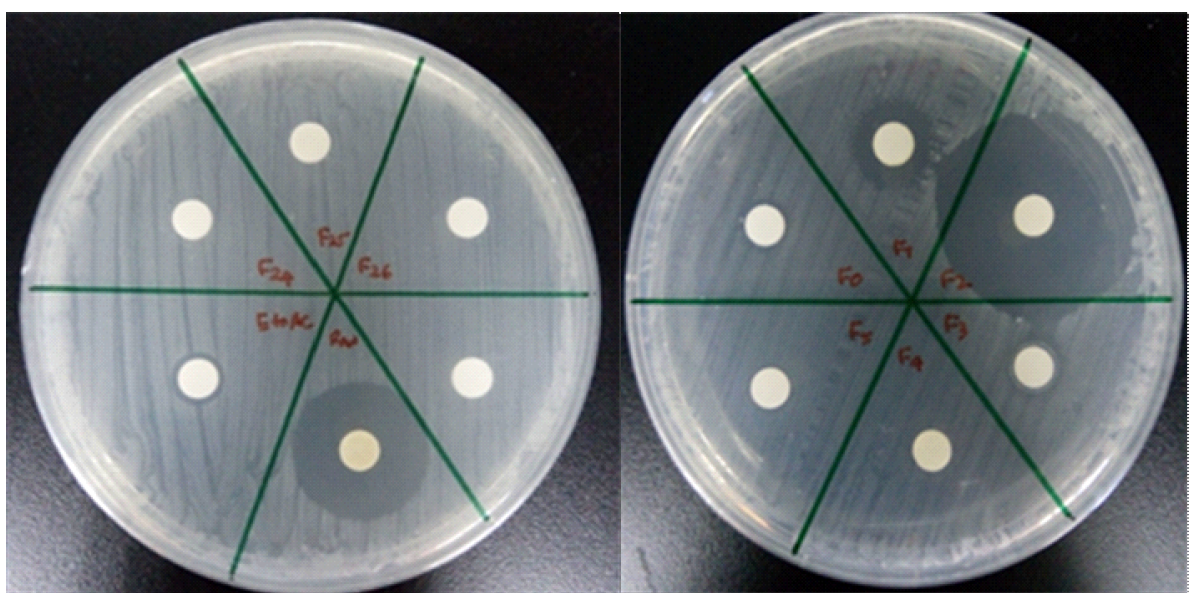
A. Before fractionation
B. After fractionation, Fraction-2

Figure 4. Clear zona of $2^{\text {nd }}$ fraction of secondary metabolite produced by MACMK-43 strain.

substrates; and MACMK-80 strain which has very weak enzymatic activity compared to others even if it has strong antimicrobial ability.

The MACMK-43 strain showed positive reaction to the following enzymatic activity: alkaline phosphatase, esterase, esterase lipase, lipase, leucine arylamidase, valine arylamidase, trypsin, acid phosphatase, Naphthol-AS-BI-phosphohydrolase, bglucosidase, esterase and $\mathrm{N}$-acetyl-bglucosaminidase, cystine arylamidase, achymotrypsin, but no enzymatic activity against agalactosidase, b-galactosidase, b-glucuronidase, and a-glucosidase. Nearly all substrates that could be degraded by MACMK-43 showed a large quantity of $>40$ nanomoles. It can be suggested that this strain has a high enzymatic potential to develop.

The MACMK-80 strain showed poor positive reaction to the following enzymatic activity: alkaline phosphatase, esterase, esterase lipase, acid phosphatase, Naphthol-AS-BI-phosphohydrolase, and a-glucosidase. All substrates that could be degraded by MACMK- 80 showed very low quantity in about 5 nanomoles. This evidence should be studied further because it is unique by its strong antimicrobial ability but weak enzymatic activity.

\subsection{Isolation and Partial Purification of Active Compounds from MACMK-43 Strain}

Hexane and ethyl acetate were used for fractionation of active compound extracts produced by MACMK-43. The selection of the solvent was based on the TLC results where the crude extract separated using hexane : ethyl acetate compared to methanol : ethyl acetate (Figure 3).

Fractionation of the MACMK- 43 crude extract was performed by chromatographic columns and yielded as many as 26 fractions. The 26 fractions were 


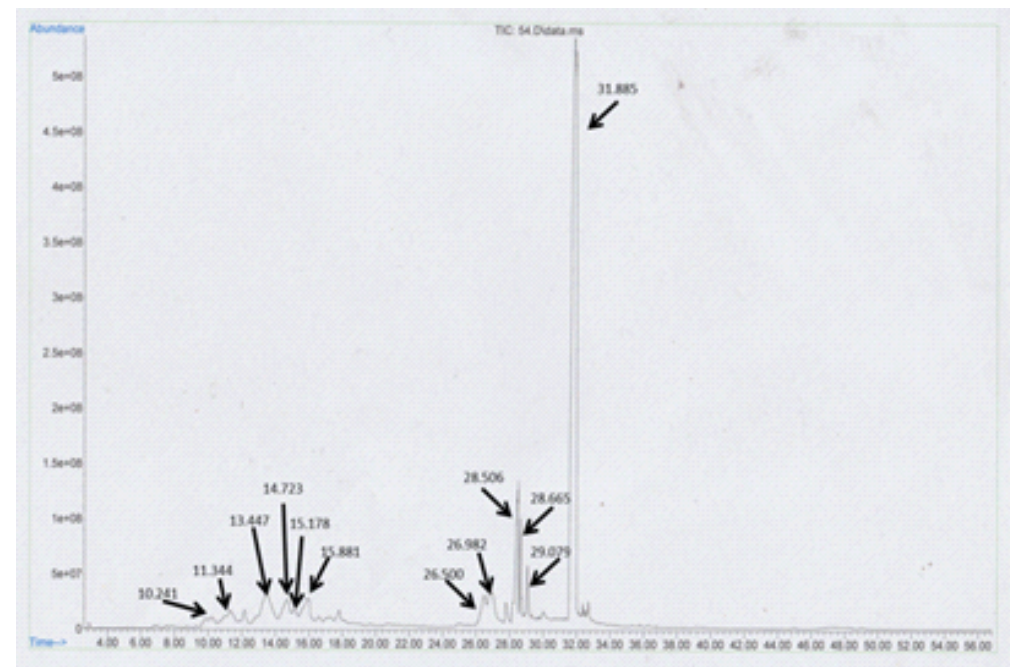

Figure 5. Chromatogram of $2^{\text {nd }}$ fraction of active metabolite produced by Streptomyces violascens strain MACMK-43, analysed using Gas Chromatography Mass Spectrophotometer (7890B, Agilent).

Table 4. Metabolite profiling of $2^{\text {nd }}$ fraction from secondary metabolite produced by MACMK-43 strain; analysed by GCMS and compared to library database in the tool

\begin{tabular}{ccclc}
\hline No & RT & Quality & \multicolumn{1}{c}{ Compound } & Percentage (\%) \\
\hline 1 & 10.241 & 38 & Benzenemethanol, ar-ethyl & 1.08 \\
2 & 11.344 & 64 & $\begin{array}{l}\text { 2-pyridinecarbonitril, 3-ethyl-1,2,5,6- } \\
\text { tetrahydro-1methyl }\end{array}$ & 1.47 \\
& & & 1H-indole, 2,3-dihydro-1,2-dimethyl & 6.44 \\
3 & 13.447 & 55 & 2,4,6-trimethylbenzyl alcohol & 3.38 \\
4 & 14.723 & 96 & Benzene, 1-ethenyl-4-methyl & 1.2 \\
5 & 15.178 & 93 & 4-methyl-1-indonone & 2.79 \\
6 & 15.881 & 60 & Phenol, nonyl & 2.94 \\
7 & 26.5 & 97 & Phenol, nonyl & 1.57 \\
8 & 26.907 & 87 & Nonyl-phenol mix of isomers & 7.25 \\
9 & 26.982 & 93 & 7,9-di-tert-butyl-1-oxaspiro[4.5]deca-6,9- & 2.67 \\
10 & 28.506 & 99 & diene-2,8-dione & 1.59 \\
11 & 28.665 & 72 & Dibutyl phthalate & 59.67 \\
12 & 29.079 & 99 & 1-methyl[2,2]paracyclophan-1-en & \\
13 & 31.885 & 90 & 4-amino-5-cyano-6-(4'methoxyphenyl)-1- & methyl-2,3-dihydropyrrolo[2,3-B]pyridine \\
& & & &
\end{tabular}

tested for resistance against $C$. albicans, and found that the most active compound was showed in the $2^{\text {nd }}$ fraction (Figure 4). The active compound of the $2^{\text {nd }}$ fraction (Figure 4B) strongly inhibited the growth of $C$. albicans compared to the raw compound before purification (Figure 4A). This indicates that the active compound has potential as antimicrobial, especially antifungal against $C$. albicans.

The chromatogram of GCMS examination is shown in Figure 5. It shows that the $2^{\text {nd }}$ fraction of active metabolite contain 12 single peaks (Figure 5). Compared to the library database of the tool, the fraction is contained of compound as seen in Table 4. The highest peak is the compound in retention time (RT) of 31.885 minutes, with the largest content of $59.67 \%$ and the quality of $90 \%$. The compound is suspected to be 4-amino-5-cyano-6(4'methoxyphenyl) -1-methyl-2,3-dihydropyrrolo [2,3B] pyridine.

Many researchers reported pyridine derivatives have varying abilities, such as $\mathrm{N}-(3,5,6$-Trichloro-2- 

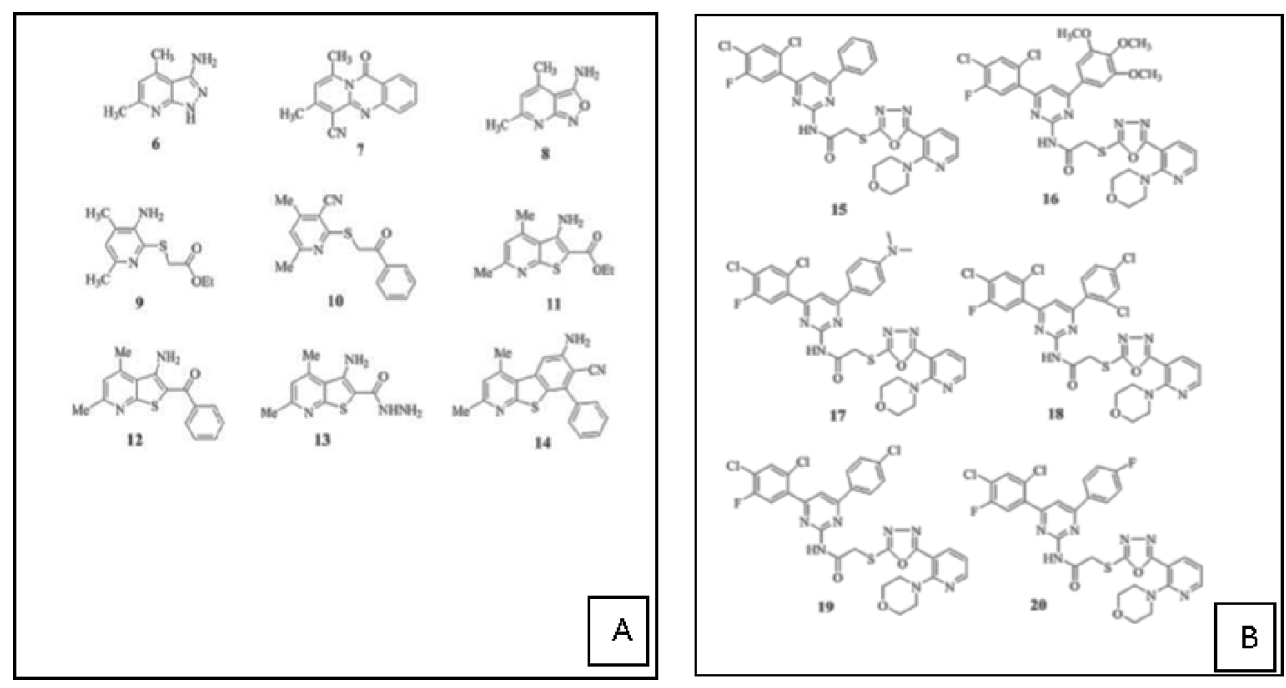

Figure 6. A. Representative examples of antimicrobial compounds containing pyridine as basic unit; B. Oxadiazole substituted Pyridine derivatives active against various bacteria (Altaf et al., 2015).

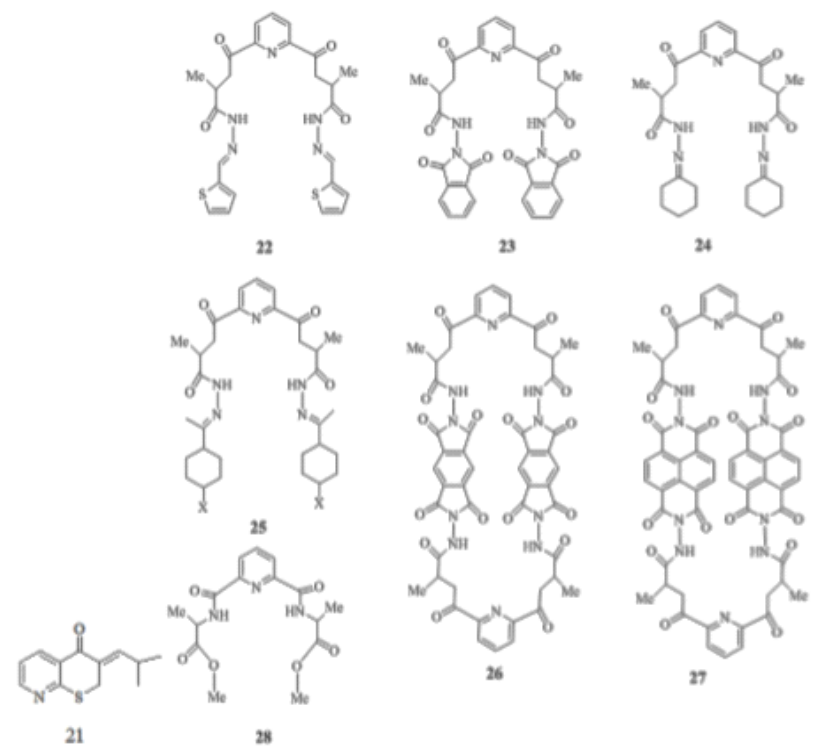

Figure 7. Oxadiazole substituted Pyridine derivatives active against various bacteria (Altaf et al., 2015).

pyridyloxyacetyl)N'-aroylhydrazines and $\mathrm{N}-(3,5,6-$ Trichloro-2-pyridyloxyacetyl)-N'arylsulfonylhydr-azines as an antibacterial activity against gram negative Eschericia coli and gram positive bacterium Staphylococcus albus, also as herbicides against Cynodon dactylone, Cyperus rotundus, Echinochola crusgalli, Euphorbia hirta, Celocia argentia, Eugenia indica and Tridax procumbens (Altaf et al., 2015), and as an antifungal agent against Aspergillus niger and Aspergillus teniussiama (Chavan et al., 2006). Octenidiene - a pyridine derivate which comprising hydrophilic and lipophilic parts - as an antimicrobial agent (Savchenko, Dorokhov, Yakushchenko, Zyuzin, \& Aldoshin, 2010). Thienopyridine and other pyridine- derived compounds of type 6-14 (Figure 6A) as antibacterial agent against gram positive $S$. aureus and gram negative E. coli, Pseudomonas aeruginosa and $P$. vulgaris (Zav'yalova, Zubarev, \& Shestopalov, 2009). The 3-hydroxypyridine-4-ones and 3-hydroxypyran-4-ones compounds active against $S$. aureus, A. niger and C. albicans (Sabet, Fassihi, \& Moeinifard, 2009). Type of 3-substituted methylene-2H-thiopyrano pyridin-4 (3H) -ones [2,3-b] compound was tested as an antifungal in vitro (Altaf et al., 2015)

Figure 6B shows several types of pyridine derivatives. Oxadiazole substituted pyridine derivatives such as compounds of types 15 and 16 showed antimicrobial activity against $E$. coli, $S$. aureus, 


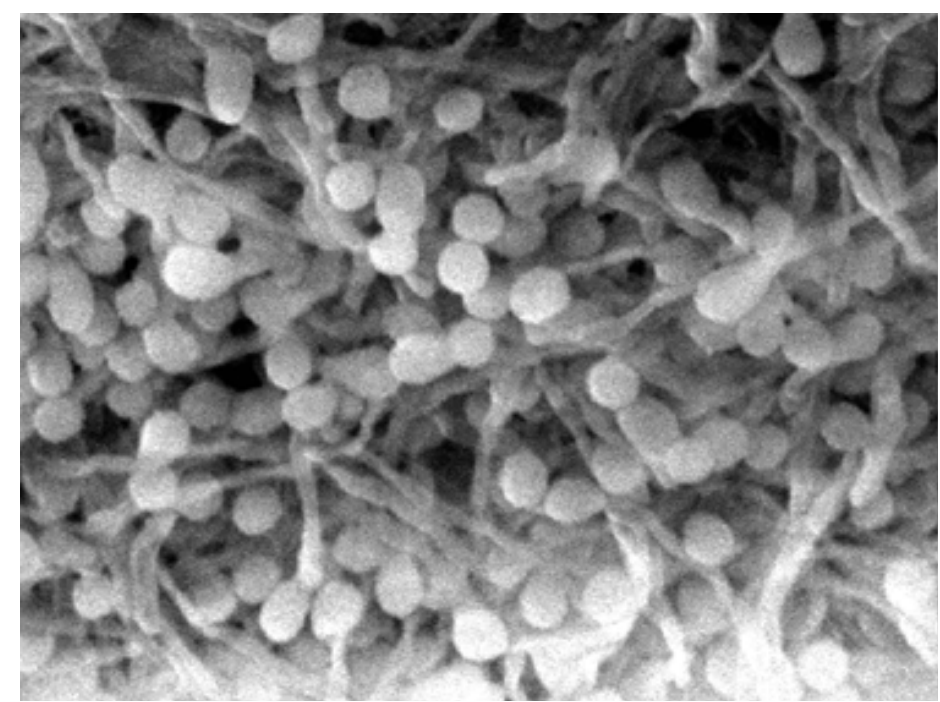

Figure 8. Photo Scanning Electronic Microscopy (JSM 5310 LV, JEOL) of MACMK-43 strain.

Salmonella typhi and B. subtitlis, the type 17 compounds have activity against $E$. coli, type 18 compound inhibited $S$. aureus, while compounds 19 and 20 were active against $S$. typhi, and type 20 compounds also exhibit activity against gram positive $B$. subtilis compared with standard drugs (Naik and Chikhalia, 2007).

Altaf et al. (2015) reported that compound 21 to 28 are macro-cyclic and open chain 2,6-substituted pyridine derivatives and also have many activities, such as activity against Microsporum gypseum, Candida krusei, and Candida glabrata, and some are almost proportional to the Ketaconazole or Ciprofloxacin (Al-Salahi, Al-Omar, \& Amr, 2010).

As mention above that many of pyridine derivatives have varied abilities in biological application, such as antimicrobial, antibacterial, antifungal, herbicide, and others (Altaf et al., 2015). Therefore, this study potential to be developed so that the ability of MACMK43 which has similarity of $97,85 \%$ with Streptomyces violascens can be further observed its ability to produce secondary metabolite, not only as antimicrobial agents.

\subsection{The Profile of MACMK-43 Streptomyces Violascens Strain by Scanning Electron Microscopy (JSM 5310 LV, JEOL)}

The profile of MACMK-43 strain under Scanning Electron Microscopy (JSM 5310 LV, JEOL) with MAG $\mathrm{X} 10,000$ condition; ACCV $20 \mathrm{kV}$; WIDTH 13.2um is shown in Figure 8. The isolate has spores and mycelium that are the typical morphology of genus Streptomyces.

\section{Conclusion}

There were 36 strains of actinomycetes obtained from the deepsea sediments of Makassar Strait that have ability to produce antimicrobial compounds. Fourteen strains inhibited the growth of E. coli, 5 strains inhibited gram positive $S$. aureus and $B$. subtilis, and 27 strains inhibited $C$. albicans. The best strain is MACMK-43 which has $97.85 \% 16 \mathrm{~S}$ rRNA gene sequence similarity with Streptomyces violascens. It produced secondary metabolite where the active fraction is suspected to be 4-amino-5-cyano6-(4'methoxyphenyl)-1-methyl-2.3-dihydropyrrolo[2,3B]pyridine which commercially used for bactericides and antihistamine.

\section{Acknowledments}

The authors would like to thank the Director of Research Center Oceanography LIPI giving the author the opportunity to participate in the expedition of Widya Nusantara 2013, Research Center for Biotechnology LIPI for conducting research and Research Center for Biology LIPI, especially Indonesian Culture Collection (InaCC) where this research was conducted. This research was funded by DIPA 2013 LIPI and LIPI Priority Program, SubProgram Food and Drug Resilience 2016.

The author also thanks Dr. Shanti Ratnakomala for supervising the observation of actynomycetes morfology, Dr. Tutik Murniasih for supervising the chemical analysis, and Dinihari Indah Kusumawardani for assisting the molecular work. 


\section{References}

Al-Salahi, R. A., Al-Omar, M. A., \& Amr, A. E. G. E. (2010). Synthesis of chiral macrocyclic or linear pyridine carboxamides from pyridine-2, 6-dicarbonyl dichloride as antimicrobial agents. Molecules, 15(9), 6588-6597.

Altaf, A. A., Shahzad, A., Gul, Z., Rasool, N., Badshah, A., Lal, B., \& Khan, E. (2015). A review on the medicinal importance of pyridine derivatives. Journal of Drug Design and Medicinal Chemistry, 1(1), 1-11.

Azman, A. S., Othman, I., Velu, S. S., Cha, K. G., \& Lee, L. $H$. (2015). Mangrove rare actinobacteria: taxonomy, natural compound, and discovery of bioactivity. Front Microbiology, 6, 856. doi: 10.3389/fmicb.00856.

Berdy, J. (2005). Bioactive microbial metabolites.Jurnal Antibiotics, 58, 1-26.

Bredholdt, H., Olga, A. G., Kerstin, E., Espen, F., Larissa, P. T., \& Sergey, B. Z. (2007). Rare actinomycete bacteria from shallow water sediments of the Trondheim fjord, Norway: isolation, diversity and biological activity. Environmental Microbiology, 9(11), 2756-2764.

Blunt, J. W., Copp, B. R., Hu W. P., Munro, M. H., Northcote, P. T, \& Prinsep, M. R. (2007). Marine Natural Products. Natural Product Reports, 24, 31-86.

Bull, A. T., Stach, J. E. M., Ward, A. C., \& Goodfellow, M. (2005). Marine actinobacteria: perspectives, challenges, future directions. Antonie Van Leeuwenhoek, 87, 65-79.

Butler, M. S. (2004). The role of natural product chemistry in drug discovery. Journal of Natural Product, 67, 2141-2215.

Chavan, V. P., Sonawane, S. A., Shingare, M. S., \& Karale, B. K. (2006). Synthesis, characterization, and biological activities of some 3, 5, 6-trichloropyridine derivatives. Chemistry of Heterocyclic Compounds, 42(5), 625-630.

Chen, P., Zhang, L., Guo, X., Dai, X., Liu, L., Xi, L., Wang, J., Song, L., .... \& Huang, Y. (2016). Diversity, biogeografi, and biodegradation potential of actinobacteria in the deepsea sediment along the Southwest Indian Ridge. Frontier Microbiology, 7, 1340. doi :10.3389/fmicb.2016.01340.

Cragg, G. M., Kingston, D. G. I., \& Newman, D. J. (2011). Development and Future Trend in Anticancer Natural Product Drug Discovery. In Cragg, G. M., Kingston, D. G. I., Newman, D. J. (Eds). Anticancer Agents from Natural Products. Taylor \& Francis Group, LLC, Boca Rotan, US. p. 699-728.

Gao, X., Lu, Y., Xing, Y., Ma, Y., Lu, J., \& Bao, W. (2012). A novel anticancer and antifungus phenazine derivate from a marine actinomycete BM-17. Microbiology Research 167, 616-622.

Hamada, M., Shibata, C., Tamura, T., \& Suzuki, K. (2013). Zhihengliuella flava $s p$. nov., an actinobacterium isolated from sea sediment, and emended description of the genus Zhihengliuella. International Journal of Systematics and Evolutionary of Microbiology, 63, 4760-4764.
Hamada, M., Chiyo, S., Nurkanto, A., Ratnakomala, S., Lisdiyanti, P., Tomohiko, T., \& Ken-ichiro, S. (2015a). Tropicihabitans flavus gen. nov., sp. nov., a new member of the family Cellulomonadaceae. Antonie van Leeuwenhoek, 107, 1299-1306.

Hamada, M., Chiyo, S., Nurkanto, A., Ratnakomala, S., Lisdiyanti, P., Tomohiko, T., \& Ken-ichiro, S. (2015b). Serinibacter tropicus sp. nov., an actinobacterium isolated from the rhizosphere of a mangrove, and emended description of the genus Serinibacter. International Journal of Systematics and Evolutionary of Microbiology, 65, 1151-1154.

Hamaki, T., Suzuki, M., Fudou, R., Jojima, Y., Kajiura, T., \& Tabuchi, A. (2005). Isolation of novel bacteria and actinomycetes using soil-extract agar medium. Journal of Bioscience and Bioengineering, 99, 485492.

Hatmanti, A., Lisdiyanti, P., Widada, J., \& Wahyuono, S. (2018). Diversity of culturable actinomycetes from deepsea floor of Makassar Strait, Indonesia. Oseanologi dan Limnologi di Indonesia, 3(2): 73-93.

Hayakawa, M., Momose, Y., Yamazaki, T., \& Nonomura, H. (1996). A method for the selective isolation of Microtetraspora glauca and related four spored actinomycetes from soil. Applied Microbiology $80(4): 375-386$. doi: $10.1111 / \mathrm{j} .1365-$ 2672.1996.tb03232

Helaly, S. E., Pesic, A., Fiedler, H. P., Sussmuth, R. D. (2011). Elaiomycins B and C: Alkylhydrazide antibiotics from Streptomyces sp. BK 190. Org Letter 13, 1052-1055.

Hong, K. (2013). Actinomycetes from mangrove and their secondary metabolites. Acta Microbiology Sinica, 53, 1131-1141.

Hong, K., Gao, A. H., Xie, Q., Gao, H., Zhuang, L., Lin, H. P., Yu, H. P., ..... \& Ruan, J. S. (2009). Actinomycetes for marine drug discovery isolated from mangrove soils and plants in China. Marine Drugs, 7, 24-44. doi : 10.3390/md7010024.

Hong, S. G., Lee, Y. K., Yim, J. H., Chun, J., \& Lee, H. K. (2008). Sanguibacter antarticus sp nov., isolated from Antarctic sea sand. International Journal of Systematics and Evolutionary of Microbiology, 58, 5052. doi : 10.1099/ijs.0.60531-0

Humble, M. W., King, A., \& Phillips, I. (1977). API ZYM: a simple rapid system for the detection of bacterial enzymes. Journal of Clinical Pathology, 30(3), 275277.

Kamjam, M., Sivalingam, P., Deng, Z., \& Hong, K. (2017). Deepsea actinomycetes and their secondary metabolites. Frontiers in Microbiology, 8, 760. doi: 10.3389/fmicb.2017.00760

Kanoh, K., Adachi, K., Katsuta, A., \& Shizuri, Y. (2008). Structural determination and proposed biosynthesis of alcanivorone, a novel á-Pyrone produced by Alcanivorax jadensis. The Journal of Antibiotics, $61(2), 70$.

Khan, S. T., Komaki, H., Motohashi, H., Kozone, I., Takagi, M., \& Kazuo, S. (2011). Streptomyces associated with marine sponge Haliclona sp.: biosynthetic genes for 
secondary metabolites and products. Environments Microbiology, 13, 391-403.

Lam, K. S. (2006). Discovery of novel metabolites from marine actinomycetes. Current Opinion in Microbiology, 9(3), 245-251.

Li, S., Tian, X., Niu, S., Zhang, W., Chen, Y., \& Zhang, H. (2011). Pseudonocardians AC, new Diazanthraquinone derivates from a deep sea actinomycete Pseudonocardia sp. SCSIO 01299. Marine Drugs, 9, 1428-1439. doi : 10.3390/ md9081428

Lu, J., Ma, Y., Liang, J., Xing, Y., Xi, T., \& Lu, Y. (2012). Aureolic acids from a marine-derived Streptomyces sp. WBF16. Microbiological research, 167(10), 590595.

Luo, Y., Jing, X., Yin, W., Jing, X., Shujie, X., \& Jun, X. (2011). Streptomyces indicus sp nov., an actinomycete isolated from deep-sea sediment. International Journal of Systematics and Evolutionary of Microbiology, 61, 2712-2716.

Manivasagan, P., Jayachandran V., Kannan S., \& SeKwon, K. (2013). Marine actinobacterial metabolites: Current status and Future perspective. Microbiological Research 168, 311-332.

Mincer, T. J., Paul, R. J., Christopher, A. K., \& William, F. (2002). Widespread and persistent population of a major new marine actinomycete taxon in ocean sediments. Applied and Environment Microbiology, 68, 5005-5011.

Naik, T. A. \& Chikhalia, K. H. (2007). Studies on synthesis of pyrimidine derivatives and their pharmacological evaluation. Journal of Chemistry, 4(1), 60-66.

Pan, H. Q., Yu, S. Y., Song, C. F., Wang, N., Hua, H. M., Hu, J. C., \& Wang, S.J. (2015). Identification and characterization of the antifungal substances of a novel Streptomyces cavourensis NA4. Jurnal of. Industrial. Microbiology and. Biotechnology, 25, 353357. doi : 10.4014/jmb.1407.07025.

Pan, H. Q., Zhang, S. Y., Wang., N., Li, Z. I., Hua, H. M., Hu, J. C., \& Wang, S.J. (2013). New spirotetronate antibiotics lobophorins $\mathrm{H}$ and I from a South China sea derived Streptomyces sp. 12A35. Marine Drugs 11, 3891-3901. doi : 10.3390/md11103891

Pathom-aree, W., James, E. M., Stach, A. C. W., Koki, H.,, Bull, A. T., \& Goodfellow, M. (2006). Diversity of actinomycetes isolated from Challenger Deep sediment $(10,898 \mathrm{~m})$ from Mariana Trench. Extremophiles, 10, 181-189.

Pesic, A., Baumann, H. I., Kleinschmidt, K., Ensle, P., Wiese, J., Süssmuth, R. D., \& Imhoff, J. F. (2013). Champacyclin, a new cyclic octapeptide from Streptomyces strain C42 isolated from the Baltic Sea. Marine Drugs, 11(12), 4834-4857.

Sabet, R., Fassihi, A., \& Moeinifard, B. (2009). Preliminary MLR studies of antimicrobial activity of some 3hydroxypyridine-4-one and 3-hydroxypyran-4-one derivatives. Research in Pharmaceutical Sciences, 2(2), 103-112.
Savchenko, V. I., Dorokhov, V. G., Yakushchenko, I. K., Zyuzin, I. N., \& Aldoshin, S. M. (2010). Developing state-of-the-art antiseptics based on pyridine derivatives. Herald of the Russian Academy of Sciences, 80(2), 149-154.

Skropeta, D., Wei, L. (2014). Recent advances in deepsea natural product. Natural Product Reports, 31, 999-1025. doi: 10.1039/C3NP70118B.

Song, Y., Li, Q., Liu, X., Chen, Y., Zhang, Y., Sun, A., Zhang, W., Zhang, J., \& Ju, J. (2014). Cyclic hexapeptides from the deep South China sea derived Streptomyces scopuliridis SCSIO ZJ46 active against pathogenic gram positive bacteria. Journal of Natural Product, 77, 1937-1941. doi: 10.1021/np500399v

Song, Y., Liu, G., Li, J., Huang, H., Zhang, X., Zhang, H., \& Ju, J. (2015). Cytotoxic and antibacterial Angucyclineand Prodigiosin- analogues from the deep sea derived Streptomyces sp. SCSIO 11594. Marine Drugs, 13, 1304-1316. doi: 10.3390/md13031304

Valli, S., Suvathi, S. S., Aysha, O. S, Nirmala, P., Vinoth, K. P., \& Reena, A. (2012). Antimicrobial potential of Actinomycetes species isolated from marine environment. Asian Pacific Journal of Tropical Biomedicine, 2(6), 469-473.

Wang, Q., Song, F., Xiao, X., Huang, P., Li, L., Monte, A., Abdel-Mageed, W.M, Wang, .......\& Zhang, L. (2013). Abyssomicins from the South China Sea Deep Sea Sediment Verrucosispora sp.: Natural Thioether Michael Addition Adducts as Antitubercular Prodrugs. Angewandte Chemie International Edition, 52(4), 1231-1234.

Xu, D. B., Ye, W. W., Han, Y., Deng, Z. X., \& Hong, K. (2014). Natural product of marine actinomycetes. Marine Drugs, 12, 2590-2613. doi : 10.3390/md12052590.

Yang, X. W., Zhang, G. Y., Ying, J. X., Yang, B., Zhou, X. F., Steinmetz, A., Liu, Y.H., \& Wang, N. (2013). Isolation, characterization, and bioactivity evaluationof 3-((6-) methylpyrazin-2yl)methyl)-1H-indole, a new alkaloid from a deep sea derived actinomycete Serinicoccus profundi sp. Nov. Marine Drugs 11, 33-39. doi: 10.3390/md11010033

Yu, J., Zhang, L., Liu, Q., Qi, X. H., Ji, Y., \& Kim, B. S. (2015). Isolation and characterization of actinobacteria from Yalujiang coastal wetland, North Cina. Asian Pacific Journal of Tropical Biomedicine, 5, 555-560. doi : 10.1016/j.apjtb.2015.04.007.

Zav'yalova, V. K., Zubarev, A. A., \& Shestopalov, A. M. (2009). Synthesis and reactions of 3-acetyl-6-methyl2-(methylthio) pyridine. Russian Chemical Bulletin, 58(9), 1939-1944.

Zhang, L., Xi, L., Ruan, J., \& Huang, Y. (2012). Microbacterium marinum sp. nov., isolated from deepsea water. Systematics of Applied Microbiology, 35, 81-85. doi : 10.1016/syapm.2011.11.004.

Zhang, G., Zhang, Y., Yin, X., \& Wang, S. (2015). Nesterenkonia alkaliphila sp. nov., an alkaliphilic, halotolerant actinobacteria from the western Pacific Ocean. Intternational Journal of Systematics and Evolutionary of Microbiology, 65, 516-521. doi : 10.1099/ijs.0.065623-0. 